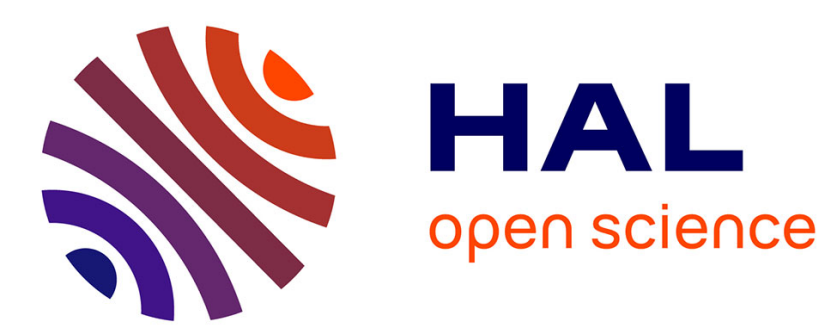

\title{
An efficient photochemical route towards triplet ethynylphosphinidene, HCCP
}

Arun-Libertsen Lawzer, Thomas Custer, Jean-Claude Guillemin, Robert Kolos

\section{To cite this version:}

Arun-Libertsen Lawzer, Thomas Custer, Jean-Claude Guillemin, Robert Kolos. An efficient photochemical route towards triplet ethynylphosphinidene, HCCP. Angewandte Chemie International Edition, 2021, 60 (12), pp.6400-6402. 10.1002/anie.202016052 . hal-03102104

\section{HAL Id: hal-03102104 https://hal.science/hal-03102104}

Submitted on 26 Jan 2021

HAL is a multi-disciplinary open access archive for the deposit and dissemination of scientific research documents, whether they are published or not. The documents may come from teaching and research institutions in France or abroad, or from public or private research centers.
L'archive ouverte pluridisciplinaire HAL, est destinée au dépôt et à la diffusion de documents scientifiques de niveau recherche, publiés ou non, émanant des établissements d'enseignement et de recherche français ou étrangers, des laboratoires publics ou privés. 


\title{
An efficient photochemical route towards triplet ethynylphosphinidene, HCCP
}

\author{
Arun-Libertsen Lawzer, ${ }^{*[a]}$ Thomas Custer, ${ }^{[a]}$ Jean-Claude Guillemin, ${ }^{[b]}$ and Robert Kołos ${ }^{[a]}$
}

[a] Dr. Arun-Libertsen Lawzer

Institute of Physical Chemistry, Polish Academy of Sciences

Kasprzaka 44/52

01-224 Warsaw, Poland

E-mail: alawzer@ichf.edu.pl

[a] Dr. Thomas Custer

Institute of Physical Chemistry, Polish Academy of Sciences

Kasprzaka 44/52

01-224 Warsaw, Poland

Email: thomas.custer@ichf.edu.pl

[a] Prof. Dr. Robert Kołos

Institute of Physical Chemistry, Polish Academy of Sciences

Kasprzaka 44/52

01-224 Warsaw, Poland

Email: rkolos@ichf.edu.pl

[b] Prof. Dr. Jean-Claude Guillemin

Univ Rennes

Ecole Nationale Supérieure de Chimie de Rennes

CNRS, IRCR-UMR 6226

F-35000 Rennes, France

Email : jean-claude.quillemin@ensc-rennes.fr

Supporting information for this article is given via a link at the end of the document.

\begin{abstract}
While the archetypal free phosphinidene, H-P, has been studied for over a century, reports on uncomplexed, univalent phosphorus compounds are very sparse. Here we demonstrate production of HCCP in solid argon through the UV-induced rearrangement and subsequent dehydrogenation of phosphapropyne, $\mathrm{CH}_{3} \mathrm{CP}$. Migration of $\mathrm{H}$ atoms along the $\mathrm{CCP}$ backbone of $\mathrm{CH}_{3} \mathrm{CP}$ resulted in production of the previously unobserved species 1phosphapropadiene, $\mathrm{CH}_{2}=\mathrm{C}=\mathrm{PH}$, followed by ethynylphosphine, $\mathrm{HCCPH}_{2}$.
\end{abstract}

Phosphinidenes, the phosphorus analogues of nitrenes, have long been known as ligands in transition metal complexes, ${ }^{[1]}$ but only a handful of the free species have been experimentally characterized. The hydride (HP), ${ }^{[2]}$ cyanophosphinidene $(\mathrm{PCN}),{ }^{[3]}$ and ethynylphosphinidene $(\mathrm{HCCP})^{[4]}$ were detected as inseparable gaseous components produced through electrical discharge or high energy irradiation. Mesitylphosphinidene was observed in a solvent following the photolysis of mesitylphosphirane. ${ }^{[5]}$ Phenylphosphinidene was later produced ${ }^{[6]}$ in a cryogenic argon matrix (just like mesitylphosphinidene) ${ }^{[7]}$ from the corresponding phosphirane. Reaction of silicon atom with $\mathrm{PH}_{3}$ also in an argon matrix, showed the presence of $\mathrm{H}_{3} \mathrm{SiP}$ (silylphosphinidene). ${ }^{[8]}$ Recently, a singlet phosphinophosphinidene, stable at room temperature, was synthesized..$^{[9]}$ All other known phosphinidenes have triplet electronic ground states.

Given the presence of $\mathrm{HCCN}^{[10]}$ and the $\mathrm{CCP}$ radical[11] in the interstellar medium, HCCP has been theorized as a potentially detectable species of astrochemical interest. ${ }^{[12]}$ The rotational spectrum ${ }^{[4]}$ and theoretical studies ${ }^{[13]}$ of HCCP indicated a linear, allenic structure, $\mathrm{H}-\dot{\mathrm{C}}=\mathrm{C}=\underline{\dot{P}}$, with a significant contribution from the $\mathrm{H}-\mathrm{C} \equiv \mathrm{C}-\underline{\dot{P}}$. electronic configuration (Tab.
S4). For $\mathrm{HCCN}^{[14]}$ the prevailing arrangement, $\mathrm{H}-\dot{\mathrm{C}}=\mathrm{C}=\dot{\mathrm{N}}$, is accompanied by a significant carbenic admixture, $\mathrm{H}-\mathrm{C}-\mathrm{C} \equiv \mathrm{N}$.A theoretical (coupled cluster) study ${ }^{[13 a]}$ did not reveal any potential energy minimum that would correspond to an analogous phosphorus-bearing carbene, $\mathrm{H}-. \dot{\mathrm{C}}-\mathrm{C} \equiv \mathrm{P}$. Although both $\mathrm{HCCX}$ species have a triplet ground state, the singlet-triplet energy gap, very small for $\mathrm{HCCN}(3 \mathrm{~kJ} / \mathrm{mol}),{ }^{[15]}$ is $75 \mathrm{~kJ} / \mathrm{mol}$ for HCCP. ${ }^{[13 a]}$

$\mathrm{HCCN}$ has been formed through photolysis of diazoacetonitrile $\left(\mathrm{N}_{2} \mathrm{CHCN}\right)$ and tentatively through VUV photolysis of acetonitrile $\left(\mathrm{CH}_{3} \mathrm{CN}\right) \cdot{ }^{[16]}$ The synthesis of the phosphorus analogue of diazoacetonitrile remains a challenge while that of phosphapropyne ${ }^{[17]}\left(\mathrm{CH}_{3} \mathrm{CP}, 1\right)$ is known. No photodegradation studies have been carried out for any $\mathrm{C}_{2} \mathrm{H}_{3} \mathrm{P}$ stoichiometry compound.

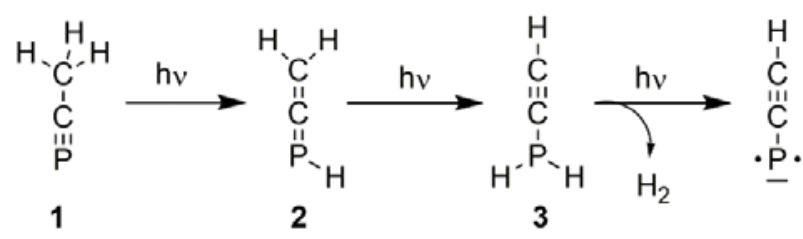

Scheme 1. Isomerisation of phosphapropyne 1 followed by dehydrogenation of ethynylphosphine 2 .

Previous studies of Guillemin et al. ${ }^{[18]}$ have shown that ethynylphosphine $\left(\mathrm{HC} \equiv \mathrm{CPH}_{2}, 3\right)$ rearranges to 1 in a reaction catalyzed by a strong Lewis base or a weak Bronsted base at high temperature in a vacuum gas-solid reaction. The authors proposed an intermediate species, phosphapropadiene $\left(\mathrm{CH}_{2}=\mathrm{C}=\mathrm{PH}, 2\right)$, although it has never been observed experimentally. Herein, we report the UV-induced rearrangement 
Table 1. IR spectroscopic identification of phosphapropadiene $\left(\mathrm{CH}_{2}=\mathrm{C}=\mathrm{PH}, 2\right)$ produced upon $\mathrm{CH}_{3} \mathrm{CP}$ photolysis

\begin{tabular}{|c|c|c|c|c|c|c|c|c|c|}
\hline & \multirow{3}{*}{ Mode $^{\text {a }}$} & \multicolumn{4}{|c|}{ Theory (B3LYP/aug-cc-pVTZ) ${ }^{\mathrm{b}}$} & \multicolumn{4}{|c|}{ Experiment (Argon matrix) } \\
\hline & & \multirow{2}{*}{$\begin{array}{l}\text { Freq. }^{\mathrm{c}} \\
\left(\mathrm{cm}^{-1}\right)\end{array}$} & \multirow{2}{*}{$\begin{array}{l}\text { Intensity } \\
\left(\mathrm{km} \mathrm{mol}^{-1}\right)\end{array}$} & \multicolumn{2}{|c|}{ Isotopic shifts $\left(\mathrm{cm}^{-1}\right)$} & \multirow{2}{*}{$\begin{array}{l}\text { Freq. } \\
\left(\mathrm{cm}^{-1}\right)\end{array}$} & \multirow{2}{*}{$\begin{array}{c}\text { Relative } \\
\text { intensity } \\
(\%)\end{array}$} & \multicolumn{2}{|c|}{ Isotopic shifts $\left(\mathrm{cm}^{-1}\right)$} \\
\hline & & & & ${ }^{13} \mathrm{CH}_{2} \mathrm{CPH}$ & $\mathrm{CD}_{2} \mathrm{CPD}$ & & & ${ }^{13} \mathrm{CH}_{2} \mathrm{CPH}$ & $\mathrm{CD}_{2} \mathrm{CPD}$ \\
\hline$v_{3}$ & PH stretching & 2222.8 & 68 & 0.1 & 653.0 & 2264.4 & 79 & 0.0 & 620.6 \\
\hline$v_{4}$ & CC stretching & 1729.4 & 79 & 22.3 & 34.8 & 1732.9 & 100 & 20.8 & 26.0 \\
\hline$v_{6}$ & $\mathrm{CH}_{2}$ rocking & 933.9 & 3.3 & 7.5 & 172.9 & 954.8 & 5.8 & 7.6 & 165.6 \\
\hline$v_{7}$ & PH bending & 865.6 & 20 & 0.4 & 235.5 & 884.9 & 57 & 0.0 & 230.4 \\
\hline v8 & $\mathrm{CH}_{2}$ wagging & 850.6 & 61 & 7.7 & 176.2 & 847.0 & 79 & 7.5 & 154.6 \\
\hline
\end{tabular}

[a] Five bands of the highest DFT-predicted IR intensity (listed here) were experimentally observed. [b] Table S2 collects all fundamental modes and Table S3 shows DFT-predicted geometry of 2 . [c] Scaling factor 0.96 .

and dehydrogenation of phosphaalkyne 1 isolated in a cryogenic argon matrix, finally leading to HCCP, with species $\mathbf{2}$ and $\mathbf{3}$ being formed en route (Scheme 1).

Precursor 1 was isolated in solid argon at a molar ratio of 1:1000 ( $\mathrm{T}=6 \mathrm{~K})$ and exposed to $\mathrm{Hg}$-lamp radiation with peak emission at $254 \mathrm{~nm}$. The progress of photoreactions was monitored using FTIR and UV/visible absorption spectroscopy.

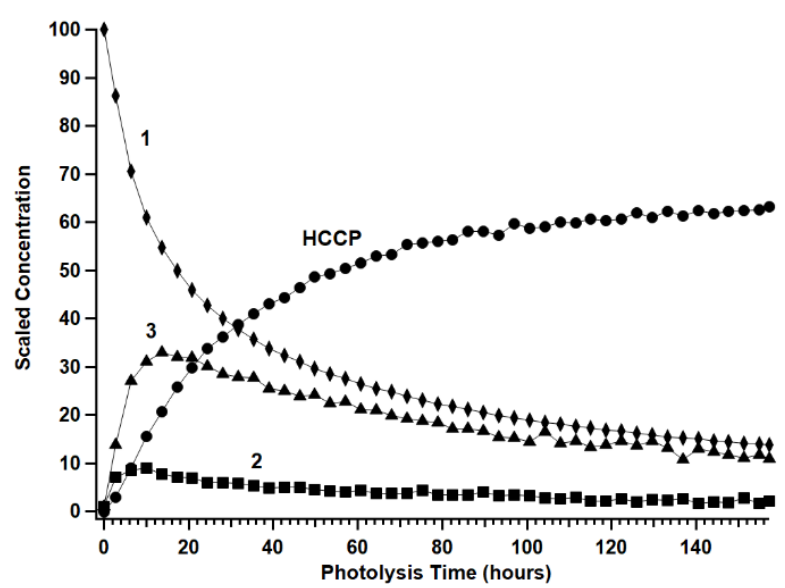

Figure 1. Evolution of concentrations over the course of $254 \mathrm{~nm}$ photolysis of $\mathrm{CH}_{3} \mathrm{CP}$ (1) in solid Ar, scaled with respect to the initial concentration of the precursor. Integrated band intensities measured at $1556 \mathrm{~cm}^{-1}(\mathbf{1}), 1733 \mathrm{~cm}^{-1}$ (2; $\left.\mathrm{CH}_{2}=\mathrm{C}=\mathrm{PH}\right), 3311 \mathrm{~cm}^{-1}\left(3 ; \mathrm{HC} \equiv \mathrm{CPH}_{2}\right)$, and $3284 \mathrm{~cm}^{-1}(\mathrm{HCCP})$ were used in conjunction with the respective B3LYP/aug-cc-pVTZ absolute IR band strengths of $43 \mathrm{~km} / \mathrm{mol}, 79 \mathrm{~km} / \mathrm{mol}, 66 \mathrm{~km} / \mathrm{mol}$, and $76 \mathrm{~km} / \mathrm{mol}$. Common ordinate scale for the species 1, 3, and HCCP; 10-fold vertical expansion for species 2 .

At early stages of irradiation, the strongest product bands are directly attributable to the phosphine 3 based on their perfect match with a reference spectrum of a freshly synthesized sample made from diethyl ethynylphosphonate ${ }^{[19]}$ (see Fig. S2 and Tab. S1 for the relevant IR-spectroscopic data). Closer analysis reveals the presence of the allenic species 2 , hypothesized in the work of Guillemin et al. ${ }^{[18]}$ Its identification is based on DFT computations assisted by photochemistry of isotopically labeled precursors, ${ }^{13} \mathrm{CH}_{3} \mathrm{CP}$ and $\mathrm{CD}_{3} \mathrm{CP}$ (Tab. 1, Tab. S2, Fig. S3). The maximum concentration of $\mathbf{2}$ is reached prior to that of $\mathbf{3}$ (Fig. 1), suggesting a stepwise hydrogen migration from methyl group towards the phosphorus atom.

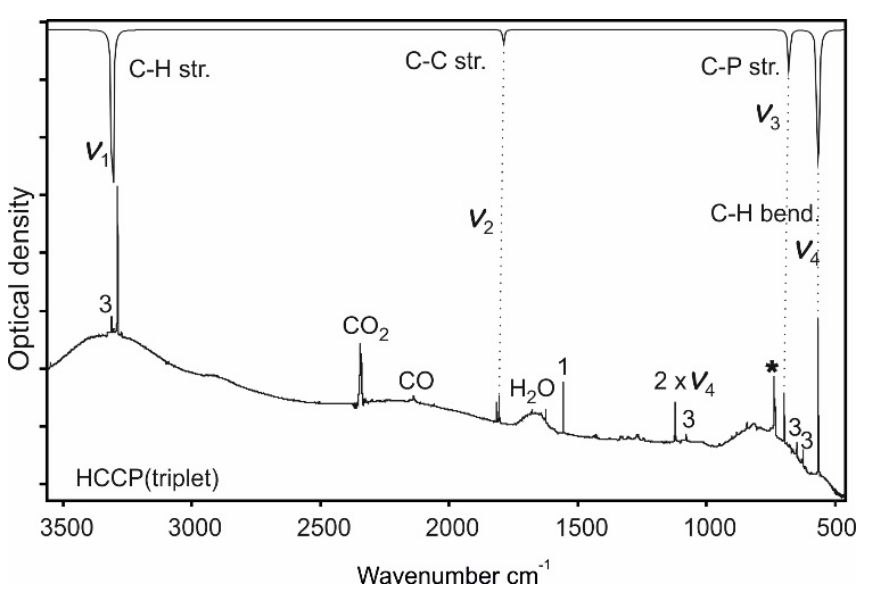

Figure 2. Identification of HCCP. Top: IR spectrum (bands pointing downwards) theoretically derived (B3LYP/aug-cc-pVTZ, harmonic approximation, scaling factor 0.96 ) for the ground triplet electronic state of HCCP. Bottom: spectrum resulting from prolonged $254 \mathrm{~nm}$ irradiation of phosphapropyne (1) in solid $\mathrm{Ar}$; $v_{1}-v_{4}$ refer to the identified bands of HCCP. Bands due to $\mathbf{1}$ and $\mathbf{3}$ (ethynylphosphine) are labeled accordingly (see Fig S4, for the IR spectrum of matrix-isolated 1). Asterisk indicates an artefact feature $\left(736 \mathrm{~cm}^{-1}\right)$ originating in the CsI substrate window.

The decay of all $\mathrm{C}_{2} \mathrm{H}_{3} \mathrm{P}$ species was observed upon prolonged photolysis (Fig. 1), and dehydrogenation turned out to be the main process. The final product, HCCP (ethynyl phosphinidene), was unambiguously identified using isotopic labelling, use of different photolysis wavelengths to identify related bands, and comparison with DFT-predicted IR spectra and their isotopic shifts as illustrated in Figs. 2 and S1. Observed experimental IR absorption data along with theoretical values, including isotopic shifts, are listed in Table 2.

In addition to aiding the identification of photoproducts experiments involving precursor 1 with ${ }^{13} \mathrm{C}$-substituted methyl group also shed light on the isomerization mechanism. Photolysis 
Table 2. IR-spectroscopic identification of ethynylphosphinidene, HCCP.

\begin{tabular}{|c|c|c|c|c|c|c|c|c|c|c|c|}
\hline & \multirow[t]{3}{*}{ Mode } & \multicolumn{5}{|c|}{ Theory (B3LYP/aug-cc-pVTZ) ${ }^{a}$} & \multicolumn{5}{|c|}{ Experiment (Argon matrix) } \\
\hline & & \multirow{2}{*}{$\begin{array}{l}\text { Freq. } \\
\left(\mathrm{cm}^{-1}\right)\end{array}$} & \multirow{2}{*}{$\begin{array}{l}\text { Intensity } \\
\left(\mathrm{km} \mathrm{mol}^{-1}\right)\end{array}$} & \multicolumn{3}{|c|}{ Isotopic shifts $\left(\mathrm{cm}^{-1}\right)$} & \multirow{2}{*}{$\begin{array}{l}\text { Freq. } \\
\left(\mathrm{cm}^{-1}\right)\end{array}$} & \multirow{2}{*}{$\begin{array}{l}\text { Intensity } \\
\left(\mathrm{km} \mathrm{mol}^{-1}\right)\end{array}$} & \multicolumn{3}{|c|}{ Isotopic shifts $\left(\mathrm{cm}^{-1}\right)$} \\
\hline & & & & $\mathrm{H}^{13} \mathrm{CCP}$ & $\mathrm{HC}^{13} \mathrm{CP}$ & DCCP & & & $\mathrm{H}^{13} \mathrm{CCP}$ & $\mathrm{HC}^{13} \mathrm{CP}$ & DCCP \\
\hline$v_{1}$ & $\mathrm{CH}$ stretching & 3307.9 & 76 & 14.5 & 0.4 & 795.8 & 3287.8 & 100.0 & 13.9 & 1.4 & 768.1 \\
\hline$v_{2}$ & CC stretching & 1786.7 & 4.6 & 26.2 & 38.2 & 83.8 & $\begin{array}{c}1814.2 \\
\text { and } \\
1807.9\end{array}$ & $\begin{array}{c}7.3 \text { and } \\
7.0\end{array}$ & 24.9 & 35.3 & 86.5 \\
\hline$v_{3}$ & $\mathrm{CP}$ stretching & 678.3 & 15 & 8.1 & 6.4 & 9.5 & 696.1 & 13 & 8.3 & 7.3 & 14.7 \\
\hline$v_{4}$ & $\mathrm{CH}$ bending & 564.6 & 36 & 4.5 & 0.8 & 112.1 & 564.7 & 73 & 4.1 & 0.4 & 116.8 \\
\hline$v_{5}$ & C-P bending & 299.6 & 10 & 1.3 & 8.5 & 20.5 & & out o & detection $\mathrm{r}$ & nge & \\
\hline
\end{tabular}

[a] Scaling factor 0.96 .

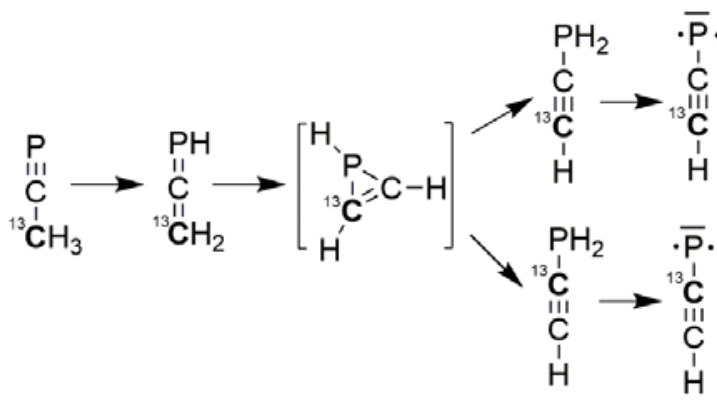

Scheme 2. Molecular rearrangements over the course of ${ }^{13} \mathrm{CH}_{3} \mathrm{CP}$ photolysis. The exact identity of a deduced CCP ring-bearing structure is unknown; see text.

of ${ }^{13} \mathrm{CH}_{3} \mathrm{CP}$ gave rise, as anticipated, to the ${ }^{13} \mathrm{CH}_{2}=\mathrm{C}=\mathrm{PH}$ isotopomer of 2. However, the formation of both $\mathrm{H}^{13} \mathrm{CCPH}_{2}$ and $\mathrm{HC}^{13} \mathrm{CPH}_{2}$ (Tab. S1 and Fig. S2), with a ratio of approx. 1:1, was observed. This suggests that the rearrangement from 2 to 3 proceeds through a phosphacyclopropene-like species (Scheme 2). Either one of the two $\mathrm{CP}$ bonds may break within a ring, leading to the two observed ${ }^{13} \mathrm{C}$-isotopomers of 3 . This scrambling is conserved upon extended photolysis where the final products $\mathrm{H}^{13} \mathrm{CCP}$ and $\mathrm{HC}^{13} \mathrm{CP}$ appear in equal amounts. The cyclic intermediate may correspond either to a saddle point or a local energy minimum of the ground or excited state (singlet or triplet) potential energy surface. Its structure may resemble $1 \mathrm{H}$ phosphirene (Scheme 2). Pertinent quantum chemical computations are under way to identify the nature of this species.

The lack of any preference for $\mathrm{H}^{13} \mathrm{CCP}$ over $\mathrm{HC}^{13} \mathrm{CP}$ among the products of ${ }^{13} \mathrm{CH}_{3} \mathrm{CP}$ photolysis implies that ethynylphosphinidene is not produced through direct dehydrogenation of either $\mathbf{1}$ or $\mathbf{2}$ but rather by loss of $\mathrm{H}_{2}$ from $\mathbf{3}$. In a separate experiment involving Hg-lamp photolysis of pure $\mathbf{3}$ in solid argon, HCCP was the final product. However, species 1 and 2 were also generated (Fig. S5), demonstrating the reversibility of photoisomerization reactions $\mathbf{1} \longrightarrow \mathbf{2}$ and $\mathbf{2} \longrightarrow \mathbf{3}$.

The course of photolysis of $\mathrm{CH} 3 \mathrm{CP}$ was also monitored using electronic absorption spectroscopy (Fig. S6), providing first insights into the electronic spectra of species 1-3 and HCCP. As photolysis progresses, the characteristic spectrum of $\mathrm{CH}_{3} \mathrm{CP}$ is gradually eclipsed by two absorption maxima at 243 and $237 \mathrm{~nm}$ by 40 minutes of photolysis. These features, tentatively assigned to species 2, disappear upon extensive irradiation while new absorption features appear, including strong bands at 277 and $259 \mathrm{~nm}$ as well as weaker features between 350 and $290 \mathrm{~nm}$, at least partially due to HCCP. None of these features can be assigned to $\mathbf{3}$ whose spectrum is featureless.

In summary, photolysis of phosphapropyne $\left(\mathrm{CH}_{3} \mathrm{CP}, 1\right)$ in a cryogenic argon matrix with mid-UV radiation results in formation of triplet HCCP. Dehydrogenation is preceded by the appearance of the $\mathrm{C}_{2} \mathrm{H}_{3} \mathrm{P}$ isomers $\mathrm{CH}_{2}=\mathrm{C}=\mathrm{PH}(2)$ and $\mathrm{HC} \equiv \mathrm{CPH}_{2}$ (3). Isotopic labelling experiments suggest passage through a 3-membered ring in the $\mathbf{2} \longrightarrow \mathbf{3}$ isomerization. This photochemical route for production of matrix isolated HCCP paves the way for the experimental exploration of its reactivity and electronic structure.

\section{Acknowledgements}

J. C. G. thanks the Centre National d'Etudes Spatiales (CNES) for a grant and the Programme National Physique et Chimie du Milieu Interstellaire" (PCMI) of CNRS/INSU with INC/INP cofunded by CEA and CNES.

Keywords: phosphinidene - rearrangement $\bullet$ phosphapropyne • photochemistry $\bullet \mathrm{HCCP} \cdot$ matrix isolation $\bullet$ phosphapropadiene

[1] a) H. Aktaş, J. C. Slootweg, K. Lammertsma, Angew. Chem. Int. Ed. 2010, 49, 2102-2113; b) A. H. Cowley, Acc. Chem. Res. 1997, 30, 445 451.

[2] J. Rostas, D. Cossart, J. R. Bastien, Can. J. Phys. 1974, 52, 1274-1287.

[3] N. Basco, K. K. Yee, Chem. Commun. 1968, 152-153.

[4] I. K. Ahmad, H. Ozeki, S. Saito, J. Chem. Phys. 1997, 107, 1301-1307.

[5] X. Li, S. I. Weissman, T.-S, Lin, P. P. Gaspar, A. H. Cowley, A. I. Smirnov, J. Am. Chem. Soc. 1994, 116, 7899-7900.

[6] A. Mardyukov, D. Niedek, P. R. Schreiner, J. Am. Chem. Soc. 2017, 139, 5019-5022.

[7] G. Bucher, M. L. G. Borst, A. W. Ehlers, K. Lammertsma, S. Ceola, M. Huber, D. Grote, W. Sander, Angew. Chem. Int. Ed. 2005, 44, 3289-3293.

[8] J. Glatthaar, G. Maier, Angew. Chem. Int. Ed. 2004, 43, 1294-1296.

[9] L. Liu, D. A. Ruiz, D. Munz, G. Bertrand, Chem. 2016, 1, 147-153. 
[10] M. Guellin, J. Cernicharo, Astron. Astrophy. 1991, 244, L21.

[11] D. T. Halfen, D. J. Clouthier, L. M. Ziurys, Astrophys. J. 2008, 677, L101L104.

[12] a) T. J. Millar, Astron. Astrophys. 1991, 242, 241-246; b) S. B. Charnley, T. J. Millar, Mon. Notice R. Astron. Soc. 1994, 270, 570-574.

[13] a) B. Hajgató, T. Veszprémi, M. T. Nguyen, Phys. Chem. Chem. Phys. 2001, 3, 895-900; b) G.-Q, Shao, W.-H. Fang, Chem. Phys. Lett. 1998, 290, 193-198; c) B. H. Boo, Z. Liu, S. Y. Lee, Theochem-J. Mol. Struct. 2001, 536, 123-132.

[14] a) Y. Endo, Y. Ohshima, J. Chem. Phys. 1993, 98, 6618-6623; b) R. A. Bernheim, R. J. Kempf, P. W. Humer, P. S. Skell, J. Chem. Phys. 1964, 41, 1156-1157.

[15] E. T. Seidl, H. F. Schaefer III, J. Chem. Phys. 1992, 96, 4449-4452.

[16] M. E. Jacox, J. Mol. Spectrosc. 1978, 71, 369-385.

[17] J.-C. Guillemin, T. Janati, P. Guenot, P. Savignac, J.-M. Denis, Angew. Chem. 1991, 103, 191-193; Angew. Chem., Int. Ed. Engl., 1991, 30, 196198.

[18] J.-C. Guillemin, T. Janati, J.-M Denis, J. Chem. Soc., Chem. Commun. 1992, 415-416.

[19] J.-C. Guillemin, P. Savignac, J.-M. Denis, Inorg. Chem., 1991, 21702173. 


\section{Entry for the Table of Contents}

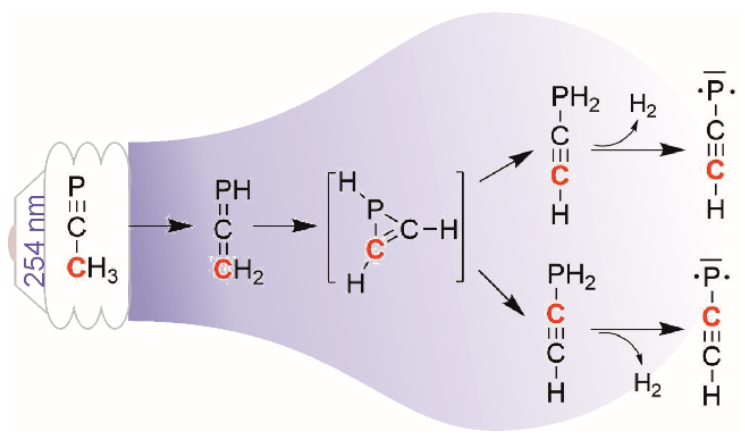

Triplet HCCP is produced as the final product of the UV induced rearrangement and subsequent dehydrogenation of phosphapropyne, $\mathrm{CH}_{3} \mathrm{C} \equiv \mathrm{P}$, in solid $\mathrm{Ar}$. Phosphaallene $\mathrm{CH}_{2}=\mathrm{C}=\mathrm{PH}$, and ethynylphosphine, $\mathrm{HC} \equiv \mathrm{CPH}_{2}$ are produced as $\mathrm{H}$ atoms are transferred along the $\mathrm{CCP}$ skeleton prior to dehydrogenation. 